\title{
Baudelaire, deux siècles après
}

\section{Aurélia Cervoni, Jean-Marc Chatelain et Andrea Schellino}

\section{OpenEdition}

\section{Journals}

Édition électronique

URL : https://journals.openedition.org/genesis/6260

DOI : 10.4000/genesis.6260

ISSN : 2268-1590

\section{Éditeur :}

Presses universitaires de Paris Sorbonne (PUPS), Société internationale de génétique artistique littéraire et scientifique (SIGALES)

\section{Édition imprimée}

Date de publication : 15 décembre 2021

Pagination : 193

ISBN : 979-10-231-0716-6

ISSN : 1167-5101

\section{Référence électronique}

Aurélia Cervoni, Jean-Marc Chatelain et Andrea Schellino, "Baudelaire, deux siècles après », Genesis

[En ligne], 53 | 2021, mis en ligne le 15 décembre 2021, consulté le 13 janvier 2023. URL : http:// journals.openedition.org/genesis/6260 ; DOI : https://doi.org/10.4000/genesis.6260 


\title{
Baudelaire, deux siècles après
}

\author{
Aurélia Cervoni, Jean-Marc Chatelain et Andrea Schellino
}

Le 9 avril 1821, Charles Baudelaire naissait à Paris, rue Hautefeuille. En décembre 1854, il écrivait à sa mère que sa vie lui semblait «damnée dès le commencement», et destinée à l'être «pour toujours »1. Mais, conscient du caractère original de son auvre, il avait promis Les Fleurs du Mal à la postérité : "Le livre est presque bien, et il restera, ce livre, comme témoignage de mon dégoût et de ma haine de toutes choses ${ }^{2}$ », écrit-il le 1er janvier 1861 à Mme Aupick. La clairvoyance de Baudelaire se mesure encore aujourd'hui à l'inactualité de son œuvre poétique et critique : en avance sur son temps, mais aussi éloignée du nôtre, troublante et auréolée d'une beauté singulière.

Plusieurs manifestations célèbrent, en 2021, le bicentenaire de la naissance de Baudelaire. Un colloque international sur «Baudelaire et les traditions poétiques », organisé par le Groupe Baudelaire de l'Institut des textes et manuscrits modernes de Paris (CNRS-ENS), en collaboration avec le CRP19 de la Sorbonne Nouvelle et le CELLF de Sorbonne Université, s'est déroulé à l'hôtel de Lauzun et à la Bibliothèque nationale de France les 18, 19 et 20 novembre 2021. Deux autres colloques, l'un à Rome ("Baudelaire et l'image», 9-10 décembre) et l'autre à Lille ("Baudelaire, la beauté du bizarre», 14-15 décembre), ont prolongé et complété cet événement scientifique. La Bibliothèque nationale de France consacre à l'auteur des Fleurs du Mal une exposition de quelque deux cents pièces (site François-Mitterrand, 3 novembre 2021-13 février 2022) : "Baudelaire, la modernité mélancolique ». Et un projet éditorial d'envergure, dont l'horizon s'étend au-delà de l'année du bicentenaire, se propose de renouveler notre compréhension de Baudelaire : la publication d'une nouvelle édition des Euvres complètes dans la Bibliothèque de la Pléiade.

Même si le dossier baudelairien peut paraître pauvre, car privé de nombreux premiers états manuscrits, l'œuvre poétique de Baudelaire se prête bien au travail génétique : les manuscrits autographes laissent apparaître un véritable "partisan de la rature». Les épreuves et les placards corrigés de l'édition originale des Fleurs du Mal, datant de mars à mai 1857, conservés à la Bibliothèque de France, témoignent du soin minutieux qu'il apportait à l'élaboration de sa poésie. La génétique baudelairienne se doit d'accorder une place majeure à la genèse éditoriale et post-éditoriale, et d'aborder des questions souvent négligées, comme la genèse de la composition des recueils et le rôle de la mise en forme typographique, dont nous évoquons quelques enjeux, en guise d'introduction aux futures recherches génétiques, dans les deux premiers articles réunis dans ce petit ensemble.

1. Charles Baudelaire, Correspondance, texte établi, présenté et annoté par Claude Pichois, avec la collaboration de Jean Ziegler, Paris, Gallimard, coll. «Bibliothèque de la Pléiade», 1973, t. I, p. 303.

2.Ibid., t. II, p. 114. 